\title{
The Cultivation Strategy of Logistics Management Students' Occupational Quality under the Background of Modern Apprenticeship System
}

\author{
Wang Yaoyan \\ Logistics Management Research Center of Yiwu Industrial and Commercial College, Yiwu City, Zhejiang \\ Province, China, 322000
}

Keywords: Modern Apprenticeship System; Logistics Management; Occupational Quality; Training Mode

\begin{abstract}
This paper mainly introduces the connotation of the modern apprenticeship, and further analysis of the logistics management of modern apprenticeship mode reform for cultivating talents in the background, at the end of the article, the author introduces the training strategy of logistics management students' occupational qualities under the system of modern apprenticeship.
\end{abstract}

\section{The connotation of modern apprenticeship system}

The so-called modern apprenticeship refers to the combination of apprenticeship training and school education, to the enterprise employment standards as the goal, to cultivate students' ability as the core, taking curriculum as a specific carrier, realize the combination of engineering, through part-time work in the form of school and enterprise cooperation, teachers and master enterprises to carry out in-depth cooperation exploring the training mode of occupation education, good talent. The modern apprenticeship system focuses on the two pronged approach of school and enterprise. Students are not just students, but also apprentices. The combination of knowledge, this is the most fundamental characteristic of the modern apprenticeship system, continuously strengthen the practice in learning, studying the process of strengthening practice, and improve students' comprehensive quality[1].

The so-called vocational ability, that is, people engaged in a comprehensive ability of a career, it can be personal knowledge of learning, skills in specific activities to show, reflecting the students' ability to undertake occupational tasks. The specific professional ability should be reflected according to the efficiency of specialized activities. The occupational ability of students majoring in logistics management mainly includes professional quality, social ability, creative ability and employment ability.

The characteristics of occupation education is to cultivate applied talents, professional logistics management requires students to cultivate highly qualified workers, need skills, service as a whole, they not only need to understand the characteristics of the industry, enterprise culture, but also need to have excellent skills, good sense of social responsibility. But now many of the traditional teaching model cannot effectively fit the needs of social development. Lack of practicality and the times, a lot of course basically has lagged behind the logistics management industry to hinder the development of students' comprehensive rhythm[2].

\section{The background of the reform for talent training mode of modern apprenticeship in logistics management}

Peter Dulac, the famous master of economic management, put forward the relation between logistics and cost saving for the first time in the journal fortune. With the passage of time, the concept of logistics is also expanding, and people's attention to logistics management has gradually improved. Especially in the last century since 80s, economic globalization gradually intensified 
competition, rapid development of information technology, many enterprises begin to the core business focus on $\mathrm{R} \& \mathrm{D}$, production and sales, they began to pay attention to the logistics management mode, logistics industry is regarded as the artery of national economic development, there is no Logistics industry, economic operation a large number of countries in goods trade will be stagnant. The majority of logistics management in colleges and universities is to train high-quality operational talents, and to create a platform for the output of this type of talents. At present, many colleges and universities have opened relevant major, and the task of training these talents must be enterprises to participate in and realize the cooperation between schools and enterprises, so as to ensure the social adaptability of logistics professionals more. On the relationship between modern logistics enterprise and the information system more closely, such as logistics data entry, tracking and feedback of relevant content, requires enterprises to establish their own information platform, information resources sharing platform also need to have some money. Logistics teaching in higher vocational colleges should be structured in transportation, transportation, pure and sorting and so on. In every aspect, the integration of scientific and technological means cannot be neglected. In the past the talent training mode, students only need to master the knowledge of teaching teachers can, under the school organization, although students can practice, but the lack of corporate culture and business understanding, only schools and enterprises to achieve double cooperation, further organize students to the classroom, teachers guide in practice explain as well as the master, to be able to get more work experience students[3].

Depending on the survey, the employment rate of higher vocational graduates is as high as 95\%, but generally speaking, the quality of employment of higher vocational students is not high. The reason lies in three aspects: first of all, the rate of professional counterparts is low, and the students' major learning is different from those in the future. Secondly, the work is not stable, after the first job after graduation in a few months a lot of higher vocational education, and the replacement of the work unit, some graduates have not completed internship and re selection unit. Poor quality of employment, reflecting the blindness of students towards employment from the side, the blind choice, so that students can adapt to work in employment, wages and salary is not high, the lack of confidence in the work of the students. Therefore, the phenomenon of job hopping is not difficult. Students lack the sense of achievement in their work, it is hard to make progress, without progress, it can no longer work in the upper level, and eventually bound to their own career development. In the traditional training, theory teaching and practice teaching are often in a disconnected state, classroom teaching is closely linked with actual teaching, students in the classroom, and can't get a good practice in the future practice, knowledge and skills learned in school and the actual work on different even though, the use of modern teaching mode, deepening teaching reform, but the drawbacks of the traditional teaching mode can not replace the specific work in the real working environment, students can quickly form a comprehensive quality and vocational ability[4].

Logistics professional training cannot be behind closed doors, must take the combination Road, can effectively improve the students' practical ability. However, there are still some problems in the process of training logistics talents in the higher vocational colleges, which lead to students cannot effectively meet the social needs. Therefore, it is necessary to realize the combination of engineering, construction of modern apprenticeship, which in modern logistics management professional, is a bold attempt, the modern apprenticeship school and enterprise common culture, common progress, common develop teaching plans, cultivate enterprise joint talents. So, how to make the logistics professional graduates can grasp the skills to achieve fit with the needs of enterprises, out of the traditional vocational education predicament, improve the training mode of the modern apprenticeship talents, this is what we need to think about and explore the issue[5].

\section{The cultivation strategy of occupational quality of logistics management students under the background of modern apprenticeship system}

The modern apprenticeship system adopts the training mode of alternation between work and study, and the students should accept the construction of the school's knowledge system, and the enterprises should accept the training of the operation process of logistics operation. During the 
school period, students not only have the identity of students, but also the training of enterprise apprentices. During the internship, companies need to pay apprentices' salaries to strengthen their loyalty to the enterprise. To shorten the vacation time, we can change the semester to the three semester system, and then let the students devote more time during the holidays to improve their practical ability. Logistics information managers need in order to keep track of orders, run management in the information system, check the warehouse situation regularly, and optimize the whole operation process. These works are not just by armchair, but needy students to accumulate experience in practice and optimize their own way of working. Schools and enterprises to achieve close cooperation, can be signed by the contract for students to be prepared for the study and employment channels, so that students can grasp the various types of work in the logistics industry. After three years of alternate training, students will be in a position to accumulate a certain amount of work experience when they graduate. In this alternate training mode, students can really get down to learning, teachers and students in the dual leadership of the teacher, through the rich operation experience, assessment of students towards a system of roads, not only by the school to say, but the school and enterprise skills test hook, so students after graduation, to become the enterprise employees, to create truly seamless resources in the labor market.

Under the background of the apprenticeship system, the teaching work should be detailed to the personnel training program and the selection of teaching materials, which need to further reflect the work concept of the enterprise and strengthen the role of practical teaching. Students can divide the study into two parts each week. They study the theory course in the first three days, and then go to the enterprise for the next two days, so that the dual education can be realized. Teachers also need to further enhance their literacy, encourage teachers to constantly improve their own ability, strengthen the school-based research work, even as a "senior logistics specialist" certificates approach, let the students learn to accept more professional theory. Truly to go to education, learning in education, these two aspects of content into one. Optimize the school resources, improve students' learning and training environment, make the school training and teaching realize complementary advantages, and jointly develop a mild talent training program. From school textbooks, curriculum system construction by the enterprise, truly achieve the goal to cultivate good talents, schools and enterprises should adhere to the cultivation of students' occupation ability as the center, covering the professional post group to carry out occupation ability analysis, according to the work of knowledge ability and quality requirements are needed, the course will be is divided into the basic professional knowledge, professional core skills etc.. In the construction of curriculum system, based on professional, professional and practical skills of the three core curriculum as the main curriculum system, the core curriculum needs in accordance with the needs of enterprises, enterprise development to meet the needs of the post project course, according to the work of the task, by the enterprise technical backbone, professional teachers to complete the project teaching activities, pay attention to students in the project development ability, so that students can participate in all aspects of the activities, to further enhance the quality of teaching management.

Higher vocational colleges need to further strengthen the construction of teachers themselves, take "bring in" and "going out", to strengthen the training of "double type" talents, specific project training for the students, in the process of the completion of training, strengthening teachers' professional skills. This will not only enable teachers to have sufficient knowledge and ability, but also further optimize their functional ability. Teachers should be encouraged to optimize their own information teaching level, carry out the teaching and research purposes of higher vocational colleges, and adopt a method of giving lectures, two divisions and expert lectures to realize the curriculum reform, so as to realize the combination of theory and practice. Students' career has to be shared by schools and enterprises. Both sides help students improve their career planning and guide students to better positions.

Only continue to strengthen the building of teachers, improve teaching quality, to further optimize the occupational qualities of students, improve the modern apprenticeship under the background of logistics management professional ability, higher vocational colleges should further strengthen their training system, starting from the budget, policy setting and other aspects, and 
school staff also need to consult. According to the characteristics of current teacher's occupation, work plan to further integrate practice. Of course, in this process, teachers must conduct a training every year, through in-depth enterprise practice, will be able to transfer more effective knowledge to students, teachers and students to enter the basic position, bear the same work with students, so as to further enhance the ability of teachers, will be more and more high quality resources into the higher vocational education, help students to achieve sound and rapid development. In general, enhance the professionalism of teachers, to improve students' ability to accept the theory that can be of major advantage, further promote students in post practice of future better development.

In order to further optimize the cooperation between schools and enterprises, it is necessary in order to do a good job in the seamless work of employment. Enterprises and schools can sign a contract to formulate personnel training programs, so as to attain the purpose of combining schools and enterprises to recruit students. At the same time, can also further from the "dual system" teaching mode, organized by logistics enterprise training, take orders class way of school enterprise cooperation, take the post as the core, the cultivation of students' skills. The team of the school and enterprise common people, output, employees and enterprises jointly set up the teachers"s teaching team, looking for reliable cooperation projects, for logistics management majors growth and professional development of enterprises and schools to explore more comprehensive road. Through the method of order training, joint admission should be strictly checks, students need a written examination and interview, the final merit, students need to enter into a contract with the enterprise, abide by the training and arrangement of enterprise in the school assignment under. At this time, students not have the identity of students, but also have the identity of apprentices. Both sides in the curriculum, in order to achieve good docking, personneltraining practice with real talent, enterprises can accord to their own characteristics, strengthen the cultivation of students' occupational skills, improve the students' core competitiveness.

\section{Conclusion}

Generally speaking, in the current higher vocational education, we cannot blindly follow the traditional teaching methods, so that students can not achieve good docking with their posts. With the social demand of talents is more and more urgent, need professional logistics base "modern apprenticeship" as the talent training mode, with social changes in demand, to further enhance the comprehensive quality and occupational skills of the logistics professional, this is a kind of scientific personnel training mode, it can effectively overcome the problems of practice and single evaluation methods the lack of the traditional teaching mode, to enable students to better fit the national needs, establish a scientific and mature training system, to promote the new talent training mode be of great advantage. The author hopes that this model can be implemented to more and more professional and post.

\section{Acknowledgements}

Fund project: Key Educational Science Planning Project of Zhejiang Province 2017, Item number: 2017SB082

\section{References}

[1] O'Connor S J. Developing professional habitus: a Bernsteinian analysis of the modern nurse apprenticeship.[J]. Nurse Education Today, 2007, 27(7):748-754.

[2] Gui-Zhen Y U. Practice and Reflection on the "Modern Master" Faculty Construction under the Background of Modern Apprenticeship[J]. Jiangsu Education Research, 2015.

[3] Feng X U. The Implementation Ways of Professional Guidance for Higher Vocational Students under the Background of Modern Apprenticeship[J]. Jiangsu Education Research, 2016.

[4] Chen D, Zhou L. To cultivate professional etiquette and ethics of vocational students under the 
Modern Apprenticeship[J]. Industrial Technology \& Vocational Education, 2013.

[5] Zhang J, Guo-Chang L I, Management D T. Study on Training Mode of Modern Apprenticeship in Hotel Management Major[J]. Journal of Dalian Education University, 2016. 